\title{
Hipnose como proposta psicoterápica para pessoas com dores crônicas
}

\author{
Hypnosis as a psychotherapeutic approach for people with chronic pain
}

Maurício da Silva Neubern

Doutor em Psicologia, professor adjunto do Departamento de Psicologia Clínica (PCL) da Universidade de Brasília, Brasília, DF - Brasil, e-mail:

mneubern@hotmail.com

Recebido: 10/11/2011

Received: 11/10/2011

Aprovado: 04/10/2012

Approved: 10/07/2012

\section{Resumo}

O presente trabalho busca destacar a hipnose como proposta psicoterápica para pessoas com dores crônicas. 0 artigo parte de uma crítica às pesquisas contemporâneas, cuja influência médica e estatística não destaca importantes dimensões clínicas presentes no processo de reconfiguração da dor crônica por meio da hipnose, principalmente no que se refere aos diferentes processos subjetivos da construção do contexto relacional, da corporeidade e da produção subjetiva dos pacientes e terapeutas. Para enfatizar a proposta hipnoterápica, o trabalho destaca três dimensões, a saber, a dor crônica como processo subjetivo, a relação entre os protagonistas do processo terapêutico e o uso da linguagem. Por fim, é concluído destacando que tal proposta não consiste apenas em uma alternativa teórica para a compreensão da relação entre hipnose e dor crônica, mas no destaque de importantes zonas de sentido dessa relação que possuem exigências teóricas e metodológicas próprias e demandam uma abordagem clínica e qualitativa.

Palavras-chave: Hipnose. Dor crônica. Psicoterapia. Subjetividade.

\section{Abstract}

This study seeks to draw attention to hypnosis as a psychotherapeutic approach for people with chronic pain. It is based on a critique of contemporary studies that present medical and statistical information that do not attribute sufficient importance to important clinical aspects of the process in which chronic pain is reconfigured through hypnosis, especially in relation to the different subjective processes of construction of the relational context, of embodiment and production of subjectivity of patients and therapists. The three dimensions used to emphasize the hypnotherapeutic approach of hypnosis are: chronic pain as a subjective process, the relationship between the characters involved in the therapeutic process, and the use of language. Lastly, the study concludes by stressing the fact that such a process is not merely a theoretical alternative for comprehending the relationship between hypnosis and chronic pain, but it also sheds light on the significant zones of meaning that entail their own theoretical and methodological requirements from a clinical and qualitative approach.

Keywords: Hypnosis. Chronic pain. Psychotherapy. Subjectivity. 


\section{Introduç̃̃o}

A retomada da hipnose como instrumento terapêutico possível no tratamento de dores crônicas padece de uma grande contradição. Ao mesmo tempo que vários estudos podem atestar sua eficácia, seja em problemas específicos, seja em termos de determinados procedimentos e técnicas (Turk, Swanson, \& Tunks, 2008) - o que justifica o interesse por ela em termos científicos e de saúde esses mesmos estudos acabam por situá-la como um procedimento linear e mecânico. A tônica presente na maior parte desses estudos é a de uma busca de padronização de procedimentos (Carli, Huber, \& Santarcangelo, 2008; Patterson, 2004), em que é verificada apenas a relação entre as intervenções e os resultados expressos pelos pacientes, que são organizados em escalas e protocolos. Desse modo, analisando as regularidades estatísticas dos resultados, os pesquisadores podem atestar, com certa confiabilidade, a influência da hipnose sobre dores de origem oncológica (Liossi, 2006), sexuais (Kandiba \& Biniki, 2003), dentre outras, e sobre temas como fibromialgia (Nogueira, Lauretti, \& Costa, 2005) e procedimentos cirúrgicos, e ainda verificar sua viabilidade em termos de grupos populacionais específicos (Jensen \& Patterson, 2006). A importância de tais estudos, além de constituírem uma geração de conhecimento em um assunto antes marginalizado, pode ser pensada também em termos epidemiológicos e de políticas públicas, sobretudo no tocante a procedimentos alternativos que não envolvam medicações e intervenções invasivas.

Contudo, há questões de grande relevância do processo hipnótico que não são contempladas nessas pesquisas, o que pode sugerir tanto uma compreensão equivocada ou insuficiente da hipnose em sua relação com a dor, como o menosprezo de dimensões subjetivas fundamentais no assunto. A princípio, tais pesquisas sugerem uma relação linear entre a prescrição hipnótica, a ordem proferida pelo terapeuta, e o efeito na dor do paciente, de maneira a desconsiderarem um conjunto de processos emocionais, interativos e simbólicos que têm lugar na modificação da experiência de dor crônica. 0 que ocorreria, portanto, em termos da mobilização emocional, da produção imaginária e de significados do paciente na reorganização de suas dores crônicas, passa no processo sem receber maiores atenções dos pesquisadores, que se mantêm ávidos apenas pelas respostas finais, aquelas que podem atender exigências estatísticas ou protocolares. Ora, se a dor é tomada como uma experiência complexa (Neubern, 2010a), que envolve processos de diferentes ordens, como biológicos, culturais e sociais, e que pode implicar ainda questões como o esquema corporal (Merleau-Ponty, 2008) e a autoimagem (Gallagher, 2008) seria realmente interessante que os pesquisadores se dispusessem a investigar como tais processos são influenciados pela hipnose e como participam em uma situação em que o paciente relata não mais sentir a dor ou, ao menos, um grande alívio. Além disso, se o foco recai sobre essa relação linear, a questão do contexto, de grande importância para a compreensão da hipnose (Stengers, 2002), não é foco de interesse dos pesquisadores, que se mantêm restritos ao controle de variáveis, mas não concebem a importância do conjunto de registros simbólicos presentes na relação clínica (Gonzalez Rey, 2007; Roustang, 2006), nem no próprio fenômeno da dor crônica que é intensamente articulada a esse contexto (Erickson, 1983; Neubern, 2009).

Nesse sentido, os estudos também parecem omitir uma dimensão importante do processo clínico - a participação do sujeito (Erickson \& Rossi, 1979). Como restringem a hipnose a uma aplicação puramente técnica, ela passa a ser concebida como um procedimento unilateral, no qual o especialista atua sobre a dor de um outro que deve permanecer passivo a suas ações; ou seja, ela se torna semelhante a qualquer intervenção externa de um especialista médico, como a cirurgia e o medicamento. A mobilização e o acesso do paciente a seus potenciais inconscientes (Erickson, 1983; Rossi \& Cheek, 1988), seu engajamento ativo no processo relacional (Roustang, 2006) e o desenvolvimento de novos significados sobre sua experiência de dor (Zeig, 2006), assim como sobre suas relações afetivas (Neubern, 2010b), constituem-se como processos de grande importância na reconfiguração da experiência de dor crônica que não são contemplados por tais pesquisas, para as quais o paciente parece ser comparado a um autômato que não toma parte em qualquer momento da transformação de sua dor. 0 que parece ser sugerido por tais estudos é que, se o alívio ou a mudança significativa de tal experiência estão puramente concentrados no poder da técnica externa aplicada por um especialista, a vivência e a participação singular do sujeito nesse processo não 
merecem importância por não se constituírem como componentes efetivos do processo de mudança.

Desse modo, o presente trabalho procura destacar a psicoterapia (Erickson \& Rossi, 1979; Neubern, 2010a) enquanto uma proposta de compreensão das relações entre hipnose e dor crônica, uma vez que nesta são contemplados importantes momentos da subjetividade do processo que são de grande relevância para um entendimento mais abrangente sobre o tema. Concebe-se aqui a psicoterapia como um processo relacional entre duas ou mais pessoas, na qual existe tanto a expertise de uma tradição de saber teórico e técnico (no caso, a hipnose de Erickson), como também uma ligação afetiva, que visam tanto o alívio ou transformação do sofrimento quanto o desenvolvimento da autonomia e a integridade do paciente. Para tanto, o trabalho enfatiza três dimensões da subjetividade ${ }^{1}$ (Gonzalez Rey, 2007) que são constitutivas de semelhante processo relacional, mas que escapam despercebidos pelas pesquisas contemporâneas: a) a dor crônica como processo subjetivo, que visa destacar uma constituição distinta do problema (Neubern, 2009), qualificando a dor como uma experiência humana que possui raízes físicas, mas também envolve dimensões sociais e culturais; b) a relação entre os protagonistas do processo, que procura ressaltar seu aspecto mútuo, como ainda a materialidade de sua vivência (Bachelard, 2004; 2007), de grande importância no desencadeamento de processos emocionais; e c) o uso da linguagem que, fugindo da lógica clássica e prescritiva, ressalta a dimensão metafórica e sistêmica de sua intervenção.

\section{A dor crônica como subjetividade}

Na perspectiva aqui discutida, a dor não é compreendida nos termos clássicos do diagnóstico médico, mas enquanto um conjunto de processos

\footnotetext{
1 A subjetividade é aqui compreendida como a constituição psíquica do sujeito que se desenvolve na dialética da inserção com seus diferentes cenários sociais (Gonzalez Rey, 2007). Ela se organiza em configurações - sistemas que integram processos emocionais e simbólicos e que podem se rearranjar ao longo do processo. A qualidade dominante que emerge de tais sistemas são os sentidos subjetivos.
}

subjetivos que se organizam de forma configuracio$\mathrm{nal}^{2}$ (Neubern, 2009). Essas configurações, denominadas por Merleau-Ponty (2005) como formas, envolvem níveis de organização distintos da experiência da pessoa, podendo implicar desde questões vitais da corporeidade, como o esquema corporal e autoimagem (Gallagher, 2008), a processos socioculturais mais amplos, próprios dos cenários nos quais o sujeito toma parte. Assim, ao mesmo tempo em que a conversação do processo terapêutico pode envolver uma investigação minuciosa sobre a forma de manifestação da dor (se ela queima, aperta, fura ou torce, em que partes do corpo ocorre e a quais padrões temporais obedece), ela também precisa envolver os temas e personagens que, de alguma forma, participam de sua constituição: o desemprego do chefe de família; o divórcio em um casamento de muitos anos; a situação de violência sofrida pelo paciente; o assédio moral no trabalho; a punição divina para os pecados; a ruptura de um projeto existencial futuro; o conflito com as heranças familiares, dentre outros. De uma entidade impessoal e independente, a dor é contextualizada como um conjunto de processos integrados à produção subjetiva dos sujeitos, seja em termos de sua corporeidade, seja em termos das diferentes pautas que estabelece com os cenários sociais. Não é sem razão que muitos sujeitos se surpreendem com o fato de que, no setting terapêutico, a conversa não se restringe à dor em si, mas abarca as questões importantes de suas vidas, envolvendo suas aspirações e personagens significativos.

Desse modo, as conversações iniciais a respeito da demanda de dores crônicas consistem uma espécie de mapeamento no qual, em conjunto com o terapeuta, o paciente discorre sobre os diferentes momentos de sua experiência (Erickson \& Rossi, 1979). Se por um lado, podem aprofundar processos a bem dizer automáticos, que escapam à

2 A descoberta de uma causalidade nem sempre é possível na experiência de dor crônica. Daí que, tanto para efeitos práticos, como para efeitos de uma alternativa teórica, é mais interessante, na perspectiva aqui adotada, compreender a dor como um sistema de processos que se articulam. Assim, a compreensão e as possibilidades de intervenção passam a obedecer a uma lógica sistêmica e complexa da subjetividade, a configuracional, e a leitura de causalidade sai da condição de exclusividade para se tornar uma leitura possível sobre o tema. 
intencionalidade (como deslocamentos da sensação, anestesias, esquecimentos e distorções temporais), podem, por outro, abordar temas comuns da subjetividade no cotidiano, como a relação com o trabalho, a família, o gênero, a religião e com as pessoas importantes nesses contextos. Tal conversação pode oferecer informações relevantes para que o terapeuta desenvolva importantes estratégias de intervenção, mas pode também abarcar uma questão ainda mais significativa para o seu processo: ela proporciona que o sujeito produza significados nos quais se torna possível conceber sua dor de outra forma (Neubern, 2010a). A dor deixa de ser uma entidade independente e onipresente, acessível apenas ao poderio da intervenção médica, para se transformar em um processo que, mesmo implicando em sofrimento, possui limitações em sua ação sobre o sujeito. Em outras palavras, ele passa a simbolizá-la de outra forma, pois pode lhe atribuir forma, cor, metáforas, intenções e ainda pode situá-la no conjunto de suas relações com o mundo cotidiano onde vive, o que proporciona consideráveis possibilidades de produção de sentidos subjetivos sobre tal experiência.

Tal momento, que se caracteriza como uma etapa inicial da hipnose, permite considerá-la como um legítimo processo psicoterápico para demandas de dores crônicas. Há aqui tanto a dimensão ativa conferida ao sujeito (Gonzalez Rey, 2007), que se assenhora do processo e começa a se tornar seu protagonista, como novas possibilidades de produção simbólica de tais demandas (Anderson \& Gehart, 2007; White, 2007). Desse modo, ele sai, de modo mais ou menos gradativo, da condição passiva típica da relação médico-paciente, para uma postura ativa na qual se utiliza de sua percepção para acionar recursos internos e sociais que permitem sua ação sobre a dor. É ele quem aponta, descreve, localiza e aprende a acionar aquilo que permite influenciar a dor, seja por aprender a se distanciar dela, seja por aprender a simbolizá-la de outra forma. Ao mesmo tempo, o foco é deslocado de uma concepção puramente orgânica, campo exclusivo da medicina, para uma dimensão sistêmica e complexa da subjetividade, uma dimensão que é acessível a sua capacidade de influência e na qual ele pode se situar como especialista: trata-se de seu próprio mundo, dos significados, sentidos, imagens e emoções gerados por ele e suas relações, e sobre os quais pode possuir alguma capacidade de influência.
No entanto, esse deslocamento traz ainda outra questão importante, na qual a dor crônica é situada no mundo vivido onde o sujeito é nativo, onde seu pertencimento se concretiza, onde sua própria identidade é forjada e desenvolvida, o que a situa como processo a ser considerado a partir do cenário dessa pessoa, em específico, como algo inserido em seus contextos sociais e trajetórias de vida. Trata-se aqui de uma ilustração concreta, em termos teóricos e metodológicos, da frase muito utilizada pelos profissionais de saúde: é necessário cuidar da pessoa e não da doença em si. Desse modo, colocando o sujeito como ativo, no sentido de qualificar sua ação e potencialidades, e nativo, em termos de situá-lo em seu próprio mundo, a hipnose se constitui como uma proposta psicoterápica, até mesmo porque tais modificações acabam por implicar em uma mudança de foco sobre o próprio corpo: ele não é mais o corpo impessoal e autômato da medicina, mas o corpo vivido, o território existencial (MerleauPonty, 2008) no qual o sujeito se inscreve no mundo e onde a dor passa a ser concebida como uma de suas expressões plenas de sentidos subjetivos.

\section{A relação e a materialidade}

Um dos primeiros pontos que constituem semelhante processo relacional é a dimensão de materialidade (Bachelard, 2007) que se produz entre terapeuta e paciente na hipnose. 0 tom diferenciado de voz, às vezes lembrando as cantigas de ninar, as pausas, a troca de olhares, o jogo de movimentos que se estabelece mutuamente proporcionam, ao mesmo tempo, dois processos de grande relevância terapêutica. Por um lado, o de uma responsividade mútua na forma de uma coreografia corporal, denominado rapport pela tradição hipnótica (Carroy, 1991), que favorece certa ruptura da alteridade (Melchior, 1998) e se caracteriza aqui pela sensação de que o terapeuta penetra o mundo do paciente, deixando ali sua voz, sua imagem, sua presença, suas ideias que servirão, mais tarde, como material sobre o qual o paciente poderá produzir novos processos subjetivos. Essa entrada no mundo do outro, também presente nas outras abordagens psicoterápicas, constituiu-se como um dos aspectos fundamentais do processo hipnótico por proporcionar o estabelecimento de vínculo e confiança, além da multiplicidade de processos materiais que 
são, a bem dizer, emprestados ao sujeito para que ele possa trabalhar sobre os novos modos de organização das formas de configuração de suas dores. Por outro lado, o rapport também é acompanhado por um teor de materialidade que envolve o próprio imaginário da relação na corporeidade do sujeito, tal como ressaltado pelos elementos que Bachelard (2004) escolhe para refletir sobre tais processos na vida ordinária. Assim, não é raro que os pacientes se refiram a experiências de um calor reconfortante (fogo), a uma fluidez que desembaraça os problemas, lava e alivia o corpo (água), uma leveza que parece tirar o peso de certas situações (ar), e uma solidez afetiva que oferece segurança e sustentação ao setting terapêutico (terra). A presença do terapeuta, sua voz, sua gestualidade e, sobretudo, a ligação afetiva entre ele e o paciente proporcionam uma vivência material que atinge a fundo o sujeito em sua corporeidade, de maneira a poder desencadear processos internos e emocionais capazes de influenciar intensamente a experiência de dor, provocando um alívio que geralmente se inicia na sessão e, ao longo do processo, pode vir a se enraizar, de modo mais definitivo, nas novas formas de organização de tais processos.

O que parece ser típico das terapias hipnóticas (Erickson, 1966; Roustang, 2006) é que a materialidade envolvida nesse processo relacional, principalmente no rapport, é utilizada de forma deliberada, sem deixar de considerar, no entanto, a vivência subjetiva do terapeuta. Assim, ao mesmo tempo que o terapeuta planeja determinadas estratégias para o desenvolvimento das sessões, por exemplo, sobre como produzir um contexto acolhedor e caloroso para um paciente em particular, ele também busca se conectar com aquilo que o paciente mobiliza em sua própria subjetividade, colocando esses processos em pauta para a construção de suas intervenções e de seu próprio papel diante do mesmo (Zeig \& Geary, 2000). Não é sem razão que o uso de termos repetitivos, redundâncias, sentenças óbvias ou truísmos (Erickson \& Rossi, 1979), que caracterizam o rapport, são também acompanhados pela construção de papéis, por parte do terapeuta, que sejam pertinentes para a demanda relacional dos pacientes. Diante de uma pessoa submissa, ele pode assumir, temporariamente, um papel autoritário; em face de uma pessoa competitiva, ele pode se tornar um desafiante contumaz; com uma pessoa fragilizada, ele pode assumir uma postura maternal e acolhedora. Semelhante conjunto complexo de influências, que envolve desde expressões pontuais até todo um modo de se relacionar, não só atua em uma das dimensões mais capitais dos pacientes com dores crônicas - o relacional - como ainda permite desencadear processos de transe hipnótico ${ }^{3}$, capazes de modificar referências inconscientes de grande relevância para a modificação da dor crônica.

É assim que o transe pode permitir desencadear processos, de alguma forma, já desenvolvidos pelo sujeito em sua corporeidade e nos diferentes registros de sua produção subjetiva, que são capazes de transformar a experiência dolorosa (Erickson, 1983). Pode, por exemplo, favorecer, por processos de distorção do tempo, vivências que alterem as referências temporais de tais pacientes, seja fazendo fluir com mais rapidez os momentos de crise da dor, seja fazendo passar mais devagar os momentos prazerosos de relaxamento. Ele pode contribuir, por meio de processos dissociativos, para uma sensação de criação de fortes barreiras de proteção em pessoas que possuem o espaço vital muito permeável aos outros e se sentem facilmente invadidas em suas relações, ponto muito comum, por exemplo, em pacientes acometidos por fibromialgia. Pode proporcionar, como nas técnicas de ancoragem, que a experiência que se expressa como um todo em seu imaginário seja, aos poucos, perpassada pela presença de outros elementos de sua história de modo a modificar as configurações atuais de sua experiência, muitas vezes marcada pela depressão. Pode ainda proporcionar uma revisão profunda da trajetória de vida, como nos casos de regressão e progressão de idade, de modo a promover a reconfiguração de sentidos subjetivos sobre temas importantes de sua vida, como suas relações, suas escolhas, seus projetos futuros e suas atitudes existenciais.

Tal perspectiva foge da relação unilateral da hipnose clássica, na qual o terapeuta prescreve e impõe, e o sujeito obediente se restringe a responder, para uma perspectiva coreográfica, na

3 Malgrado a existência de grande controvérsia na definição do transe (Stengers, 2001), adota-se aqui a concepção de que o transe é um estado caracterizado por um conjunto de alterações das referências eu-mundo da pessoa, que inclui as referências ordinárias de tempo, espaço, outro e matéria (Ellenberger, 2004) que adotam outro tipo de funcionamento, concebido aqui como inconsciente (Erickson \& Rossi, 1979). 
qual terapeuta e paciente se movimentam em uma dança relacional que os mobiliza em sua corporeidade, de modo a ativar processos internos profundos (Roustang, 1991; 2006). A experiência de dor crônica passa por uma modificação substancial na forma de ser concebida, pois de uma entidade que recebe a ação de mão única de medicamentos e cirurgias, ela é concebida como um processo vivido, situado no entrecruzamento de toda uma rede de interações subjetivas que a influenciam. Mobilizamse processos pré-verbais (Roustang, 1991), imaginários (Bachelard, 2004), dramáticos (Zeig, 2006) e emocionais (Gonzalez Rey, 2007), que são colocados como integrantes da pauta interativa e possuem considerável capacidade na reconfiguração da vivência de dor crônica dos pacientes. É interessante notar como a mobilização de semelhantes processos, associados a todo um jogo específico de linguagem, possui uma eficácia nada desprezível na modificação da dor crônica, seja na promoção quase imediata de alívio, seja na modificação da forma de o paciente passar a concebê-la.

Nesse sentido, a qualidade da relação torna-se um ponto fundamental da psicoterapia hipnótica, tanto por implicar seus protagonistas nesse movimento de influência mútua, como por desencadear processos internos dificilmente acessíveis de outro modo. Ela implica em uma ligação afetiva, o vínculo, e na movimentação de seus protagonistas, dentro de um processo coreográfico, em termos corpóreos (Roustang, 2000; 2006), que passa a moldar a experiência de dor em diferentes níveis. A materialidade de semelhante coreografia, muito distinta da relação estática médico-paciente, chama a atenção por envolver o desencadeamento de processos profundos e distantes das deliberações racionais do sujeito, aqui concebidos como fenômenos hipnóticos (Erickson, 1983). É possível que o acesso a esse nível de experiência profundo, talvez ligado aos níveis corpóreos e vitais de Merleau-Ponty (2005), possua consideráveis possibilidades terapêuticas por favorecer modificações em configurações de dores crônicas aí presentes que nem sempre se encontram representadas na fala do sujeito ou em suas expressões conscientes, mas parecem atuar decisivamente na manutenção do sistema mais amplo que caracteriza tais configurações. A abordagem de tais raízes depende, portanto, dessa materialidade que evoca o emocional das relações, muitas vezes anterior à fala, e é capaz de favorecer novas formas de organização nos complexos sistemas da corporeidade vivida dos sujeitos.

Deve-se destacar ainda que semelhante noção de materialidade (Bachelard, 2007; Ellenberger, 2004) constitui-se em uma proposta de grande importância para a psicoterapia hipnótica por propor uma noção de matéria muito distinta da matéria impessoal e inerte do corpo na medicina. Ela se constitui enquanto processos imaginários (Sartre, 2005), em suas dimensões cinestésicas, simbólicas e emocionais, algo que se manifesta de uma forma concreta na vida das pessoas e que costuma surpreender os pacientes sobre seus efeitos nas dores crônicas que, por meio dessa proposta, tornam-se matérias primas passíveis de serem moldadas pelos mesmos de acordo com o modo particular em que estes se implicam no imaginário. A concretude aqui ressaltada torna-se, assim, de grande relevância, tanto por se oferecer para o trabalho ativo e transformador do sujeito, como para evitar uma velha acusação muito comum nos meios de saúde, segundo a qual se algo é imaginário, é porque simplesmente não existe ou é mera invenção do paciente (Chertok \& Stengers, 1989). Todavia, o que se pode verificar por meio de uma análise clínica acurada é que os processos imaginários mostram-se de grande valia na modificação da emocionalidade que constitui as dores crônicas, e de processos sistêmicos mais amplos onde ela toma parte, como o esquema corporal e a autoimagem. Os resultados de estudos nesse sentido (Chertok, 1998; Neubern, 2010b; Rossi \& Cheek, 1988) apontam na direção de uma dimensão ontológica concreta de tais experiências que sugere não só uma perspectiva mais ampla de saúde, como a falta de fundamento teórico e metodológico de tal acusação.

\section{0 uso da linguagem}

No entanto, além dessa utilização deliberada, por parte do terapeuta, de importantes momentos da materialidade relacional, o contexto terapêutico da hipnose voltada para pacientes acometidos por dores crônicas é marcado por uma forma muito particular de utilização da linguagem. Nesse sentido, existe uma verdadeira ruptura com as formas tradicionais de utilização da linguagem hipnótica (Martins \& Batista, 2002) que se caracterizam por prescrições diretas voltadas para a produção de 
uma ou mais respostas específicas. Tal como aqui destacado (Erickson, 1959; 1966; 1983) a linguagem se caracteriza muito mais como uma estrutura de significados (frame) que é oferecida ao sujeito para que ele mesmo reconfigure e desenvolva processos de sua própria singularidade sobre os temas que perpassam sua experiência de dor crônica. Desse modo, além de perpassar os processos materiais descritos acima, desencadeando processos automáticos por meio de redundâncias, repetições, paradoxos e expressões subliminares, o uso da linguagem hipnótica pode ser caracterizado por duas questões básicas, altamente entrelaçadas.

Primeiramente, trata-se de um conjunto simultâneo de sugestões, como ocorre nas histórias e nas metáforas, que não são colocadas de modo impositivo para o sujeito, mas como algo a ser oferecido casualmente a ele. Como o terapeuta não revela suas intenções ao se utilizar desse recurso, nem pede que o paciente reflita deliberadamente sobre isso, e o paciente está engajado ou em vias de se engajar na relação terapêutica, a história contada no setting terapêutico se afigura ao paciente como uma espécie de convite ao qual ele responde de modo quase espontâneo, por meio de associações internas que cria sem se sentir pressionado para tanto. Desse modo, essas complexas estruturas de significados (Lakoff \& Johnson, 2003) ao invés de se fixarem, como na hipnose clássica, em respostas isoladas escolhidas por alguém externo (o terapeuta), oferecem material para que o sujeito, mesmo que inconscientemente, trabalhe sobre uma diversidade de demandas e necessidades selecionadas por ele mesmo e que estão configuradas em diferentes níveis de suas experiências de dores crônicas. Uma vez que as demandas se organizam em sistemas internos, as configurações subjetivas (Gonzalez Rey, 2007), tais formas de intervenção se mostram coerentes por envolverem vários elementos desse sistema simultaneamente, de maneira a possibilitar novas formas de articulação entre os mesmos.

Possuindo semelhança simbólica com as temáticas vividas pelo sujeito, as histórias oferecem material para que suas demandas sejam trabalhadas em diferentes níveis de vivência da dor, em um processo no qual o sujeito se torna cada vez mais ativo, tanto pela eleição que faz sobre o que será trabalhado, como na atuação que desenvolve ao longo da reconfiguração da experiência. É assim que tais técnicas podem ser de grande valia para que o sujeito estabeleça novas relações com sua dor crônica, ou com elementos e pessoas essenciais na vivência desta, de modo a repensar seus papéis, suas formas de inserção social e suas atitudes perante o fluir existencial da vida, o que implica em importantes modificações na produção de sentidos subjetivos ligados a momentos centrais desse processo. Em suma, as histórias que são oferecidas, e não impostas, proporcionam considerável gama de opções de organização configuracional, como também favorecem a possibilidade de que o sujeito atue com liberdade no processo terapêutico.

Em segundo lugar, além de se constituírem como estruturas sempre abertas para o encaminhamento ou construção de soluções, sendo metáforas ativas e não mortas, tais histórias ressaltam o caráter ativo de um protagonista que, de algum modo, será associado pelo sujeito para que também possa assumir um papel ativo no processo terapêutico. 0 protagonista pode ser um rio que vence obstáculos para chegar ao mar, a sabedoria do corpo que mobiliza elementos de defesa contra a doença, uma criança que supera limitações para aprender a ler e escrever, em suma, alguém que se encontra em uma situação simbólica de dificuldades semelhantes às do paciente e consegue encontrar, por meio de seus próprios recursos, algum caminho para lidar com o problema que o aflige. Desse modo, a história atua no sentido de estabelecer relações do sujeito com diferentes elementos de sua experiência, ao mesmo tempo que o situa na condição de alguém que pode atuar nesse contexto e modificar, em algum nível, essas relações. Trata-se de um processo também muito destacado na terapia narrativa (Anderson \& Gehart, 2007; White, 2007), no qual o problema deixa de coincidir com a identidade da pessoa e se torna algo separado dela, algo com que ela possa estabelecer uma relação capaz de modificar o império dessa experiência que por vezes parece subjugar ou escravizar o sujeito.

Como o transe envolve uma modificação radical, malgrado temporária, das referências de mundo, é possível que o mergulho nesse estado, associado à riqueza de possibilidades trazida por tais usos da linguagem, favoreçam a abertura de soluções que até o momento o sujeito não havia vislumbrado por se sentir paralisado diante das diversas limitações impostas pela dor crônica. Desse modo, mergulha em um estado que é protegido e acolhedor e, ao mesmo tempo, modifica suas referências de tempo, 
espaço, linguagem e relação com o outro. Essas alterações parciais recebem uma gama intensa de arranjos de significados veiculados por tais jogos de linguagem e, impulsionadas por diferentes elementos do processo terapêutico (como o sofrimento do sujeito, seu engajamento e papel ativo na terapia), favorecem a construção de alternativas de diferentes tipos para o problema vivido pelo sujeito. A reconfiguração de mecanismos automáticos de dor ligados a uma artrite reumatoide, como a modificação de sentidos subjetivos sobre o papel desse mesmo paciente em suas relações familiares, pode ser fermentada e desenvolvida por meio desse curioso processo em que o transe envolve e trabalha, ao mesmo tempo, dimensões automáticas e simbólicas da experiência de dores crônicas. As histórias, os contos e as metáforas na hipnose parecem veicular, em suma, a ideia que faz coincidir a ação do sujeito, engendrada a partir de seus próprios recursos, e a plasticidade da experiência de dor, o que se constitui em um dos pontos mais importantes do processo terapêutico para pessoas com tais demandas (Erickson, 1959; 1966), tanto por colocar a ação como algo acessível ao paciente, como por tirá-lo da perspectiva de que apenas intervenções externas, sobre as quais ele não possui o menor domínio (como medicamentos e cirurgias), podem auxiliá-lo em seu processo.

\section{Considerações finais}

A importância de se destacar dimensões que são visualizadas e qualificadas pela psicoterapia, por serem acessíveis a um olhar essencialmente qualitativo, traz à tona não apenas a perspectiva de uma alternativa de compreensão teórica, mas de espaços da realidade empírica, zonas de sentido ${ }^{4}$ (Gonzalez Rey, 2005), que compõem tanto a experiência de dor crônica como a prática da hipnose. Essas zonas de sentido possuem exigências próprias que precisam ser contempladas pelo arsenal teórico e metodológico do pesquisador para que sejam acessíveis ao diálogo produtivo da pesquisa. A concepção da dor como subjetividade remete à discussão, em um primeiro momento, da complexidade

\footnotetext{
4 Zonas de sentido são espaços do real que se tornam inteligíveis ao pensamento do pesquisador (Gonzalez Rey, 2005).
}

de sua construção, uma vez que foge da visão exclusiva do pensamento médico e biológico, para situar-se na própria vida cotidiana do sujeito, na qual há enraizamentos simbólicos e afetivos de diferentes ordens (gênero, cultura, religião, família, emprego, entre outros). Tal como vivido pelos sujeitos, há aqui a exigência de uma compreensão que articule a complexidade de tal tecido e, ao mesmo tempo, o qualifique como processo humano no qual os sujeitos se inserem e se identificam, porque diz das realidades que vivenciam. Aqui, como nas outras dimensões destacadas, é fundamental que se ofereça outro papel ao paciente, um papel no qual as questões cotidianas de seu dia a dia recebam a mesma importância que as questões médicas recebem, e que sua condição ativa seja ressaltada e aproveitada a favor do processo terapêutico, ideia que se mostra em sintonia com as discussões recentes sobre cidadania e saúde (Ceccim \& Merhy, 2009).

Já a dimensão relacional, com toda a materialidade que a perpassa, merece um destaque especial principalmente por enfatizar a importância da emocionalidade e dos processos imaginários presentes na reconfiguração da experiência. Não se trata apenas de considerar a confiança mútua que se estabelece entre terapeuta e paciente, mas de compreendê-la em seus aspectos qualitativos, como ela se configura, que realidade cria entre ambos e, sobretudo, o que proporciona para que os sujeitos se engajem e construam a mudança (Neubern, 2010a; 2010c). Em outras palavras, compreender como emoções e imagens, em um contexto relacional específico, podem atuar decisivamente na modificação das experiências de dores crônicas consiste em um interessante e relevante campo de estudo, inclusive por alertar para a necessidade de que tal dimensão seja considerada nas intervenções profissionais. Parafraseando Binswanger (2008), a técnica, malgrado sua importância em termos de poder de transformação, fica descaracterizada sem esse solo afetivo típico das relações humanas que permite que as mudanças aconteçam, o que precisa ser contemplado na pesquisa e intervenção profissional das dores crônicas.

De modo similar, o uso da linguagem, como destacado, aponta para uma dimensão muito além da lógica intervenção-resposta, típica das pesquisas contemporâneas, ressaltando aspectos de fundamental importância para a compreensão do tema. Aqui se enfatiza a dimensão de produção de sentidos 
e histórias dos pacientes, o que situa a experiência de dor crônica e o processo hipnótico como processos humanos que precisam ser concebidos desse modo para serem coerentemente abordados. Nesse sentido, a exigência teórica e metodológica aponta para a dor crônica como um processo sistêmico e único para cada sujeito, que envolve um conjunto de produções subjetivas distintas, que necessitam ser contempladas em sua singularidade em nome da legitimidade da pesquisa e da intervenção profissional. A questão, portanto, não é apenas a eficácia em termos de alívio ou mudança da dor, mas da abertura para uma abordagem de seu aspecto sistêmico, construído em termos simbólicos e vividos a partir de diferentes contextos, e de como o sujeito pode modificar tais sistemas de modo a transformar também a qualidade das narrativas ligadas a sua experiência. Efetivamente, as formas pelas quais antigas práticas humanas, como a contação de histórias, o uso de metáforas e os jogos de palavras, conseguem atuar em uma dor neuropática ou na dor oriunda de uma artrite reumatoide remetem a uma dimensão da maior relevância para as pesquisas sobre o tema.

Em suma, o reconhecimento dessas dimensões, não simplesmente como noções, mas como perspectivas conceituais típicas da psicoterapia que se entrelaçam a importantes zonas de sentido do empírico, consiste em uma condição de grande relevância para o estudo desse tema por duas grandes razões. Primeiramente, ele apela para a própria coerência das pesquisas que, para resguardar sua legitimidade, não devem desprezar importantes facetas dos fenômenos estudados, inclusive no sentido de buscar atender suas exigências em termos teóricos e metodológicos. Se a vivência das dores crônicas se constitui como um processo sistêmico formado pela articulação de distintos processos subjetivos, ligados aos diferentes momentos de inserção do sujeito no cenário social, a abordagem da mesma não deve se constituir em uma ótica instrumentalista e linear, mas como um processo qualitativo de construção (Gonzalez Rey, 2005; Moustakas, 1994; Neubern, 2010a). Assim, em vez de esperar avidamente pela aparição da resposta a um instrumento, o pesquisador deve se colocar disponível para diferentes focos de indicadores que podem se constituir durante a pesquisa: a qualidade da relação que os sujeitos desenvolvem, que contexto ambos constroem, que papéis desempenham, como essa dor se configura nos cenários de sua existência e como a hipnose a aborda no sentido de promover sua reorganização. Essa perspectiva não significa uma cruzada contra outras propostas de pesquisa, como as instrumentalistas, mas apenas procura ser coerente com uma visão mais ampla do objeto sistêmico que se estuda, ou seja, a dor como vivência subjetiva de um sujeito e suas complexas relações com as influências hipnóticas.

Em segundo lugar, essa proposta se constitui como um resgate da ética enquanto proposta de compreensão do sujeito situado em seu lugar no mundo, em seu ethos (Figueiredo, 1996). À medida que sua condição de sujeito toma lugar central no processo terapêutico, trabalhando por sua autonomia e integridade, o contexto terapêutico se transforma em algo que é legítimo para ele, pois é seu mundo que será trabalhado, um mundo constituído por sua produção subjetiva, que abarca tanto suas questões pessoais como as pessoas de seu mundo de relações. Não é o mundo médico ou o saber técnico de hipnose (temas sobre os quais ele tem pouco a dizer) que ficam em foco e compõem o setting do processo terapêutico, mas seu próprio cenário de produção subjetiva, na qual ele é especialista e a relação com o terapeuta assume o caráter de parceria. A hipnose, enquanto processo psicoterápico, torna-se assim tanto uma forma de ajudar o sujeito a lidar tanto com a transformação imediata da dor quanto um modo mais profundo de reconciliação consigo mesmo, que envolve ambos sua identidade e seu nicho afetivo de relações (Binswanger, 2008). Assim, a questão não se limita a um mero alívio dos sinais físicos da dor, mas a um momento de reflexão e simbolização que pode assumir outros sentidos que podem levá-lo a pensar radicalmente em sua própria existência, na forma como se conduziu até aqui por nesse percurso. Nesse sentido, não é por acaso que alguns pacientes chegam a asseverar, parafraseando Viktor Frankl, (1988) que apesar de todo o maltrato e sofrimento promovidos pela dor crônica, ela os levou a pensar a vida e suas relações longe da superficialidade habitual, chegando a uma profundidade e qualidade emocional que, talvez sem seu concurso, jamais poderiam ter atingido.

\section{Referências}

Anderson, H., \& Gehart, D. (2007). Collaborative therapy. New York: Routledge. 
Bachelard, G. (2004). La terre et les rêveries de la volonté. ( $2^{\text {a }}$ ed.). Paris: Corti.

Bachelard, G. (2007). L'Air et les songes. Essai sur l'imagination du mouvement. Paris : José Corti.

Binswanger, L. (2008). De la psychothérapie. In L. Binswanger. Introduction à l'analyse existentielle. (pp. 119-147). Paris : Minuit.

Carli, G., Huber, A., \& Santarcangelo, E. (2008). Hypnotizability and chronic pain: An ambiguous connection. Contemporary Hypnosis, 25(2), 65-77.

Carroy, J. (1991). Hypnose, sugestion et psychologie. L'invention du sujet. Paris: Puf.

Ceccim, R., \& Merhy, E. (2009). Um agir micropolítico e pedagógico intenso: a humanização em laços e perspectivas. Interface (Botucatu), 13 (1), 531-542.

Chertok, L. (1998). Le non savoir des psys. Paris: Seuil/ Synthelabo.

Chertok, L., \& Stengers, I. (1989). Le coeur et la raison. Paris: Payot.

Ekeland, T-J. (1997). The healing context and efficacy in psychotherapy. Psychotherapy and the placebo phenomenon. International Journal of Psychotherapy, 2(1), 135-144.

Ellenberger, H. (2004). A clinical introduction to psychiatric phenomenology and existential analysis. In R. May, E. Angel, \& H. Ellenberger (Org.), Existence (pp. 92-125). New York: Jason Aronson Book.

Erickson, M. (1959). Hypnosis in painful terminal illness. American Journal of Clinical Hypnosis, 1, 117-121.

Erickson, M. (1966). The interpersonal hypnotic technique for symptom correction and pain control. American Journal of Clinical Hypnosis, 8, 198-202.

Erickson, M. (1983). An introduction to study and application of hypnosis in pain control. In M. Erickson, Healing in hypnosis (pp. 217-277). New York: Irvington.

Erickson, M., \& Rossi, E. (1979). Hypnotherapy: An exploratory casebook. New York: Irvington.

Figueiredo, L. (1996). Revisitando as psicologias. Petrópolis: Vozes.

Frankl, V. (1988). The will to meaning. New York: Meridian Book.
Gallagher, S. (2008). The phenomenological mind. New York: Routledge.

Gonzalez Rey, F. (2005). Pesquisa qualitativa e subjetividade. São Paulo: Thomson.

Gonzalez Rey, F. (2007). Psicoterapia, subjetividade e pós-modernidade. São Paulo: Thomson.

Jensen, M., \& Patterson, D. (2006). Hypnotic treatment of chronic pain. Journal of Behavioral Medicine, 29(1), 95-124.

Kandiba, K., \& Biniki, Y. (2003). Hypnosis as a therapy of vulvar vestibulitis syndrome: a case report. Journal of Sex and Marital Therapy, 29(2), 237-242.

King, B., Nash, M., Spiegel, D., \& Jobson, K. (2001). Hypnosis as an intervention in pain management. A brief review. International Journal of Psychiatry and Clinical Practice, 5, 97-101.

Lakoff, G., \& Johnson, M. (2003). Metaphors we live by. Chicago: Chicago University Press.

Liossi, C. (2006). Hypnosis in cancer care. Contemporary Hypnosis, 23(1), 47-57.

Martins, F., \& Batista, A. (2002). Atos de fala e hipnose. Psicologia em Revista, 8(11), 92-104.

Melchior, T. (1998). Créer le Reel. Hypnose et thérapie. Paris: Seuil.

Merleau-Ponty, M. (2005). La structure du comportement ( $3^{\text {a }}$ ed.). Paris: Puf.

Merleau-Ponty, M. (2008). Phénoménologie de la perception. Paris: Gallimard.

Moustakas, C. (1994). Phenomenological research methods. Thousand Oaks: Sage Publications.

Neubern, M. (2009). Hipnose, dor e subjetividade: Considerações teóricas e clínicas. Psicologia em Estudo, 14(2), 303-310.

Neubern, M. (2010a). Psicoterapia, dor e complexidade: Construindo o contexto terapêutico. Psicologia: Teoria \& Pesquisa, 26(3), 515-523.

Neubern, M. (2010b). Hipnose e subjetividade: utilização da experiência religiosa em psicoterapia. Estudos de Psicologia (Campinas), 27(2), 235-245.

Neubern, M. (2010c). 0 terapeuta e o contrato terapêutico: em busca de possibilidades. Estudos e Pesquisas em Psicologia, 10(3), 882-897. 
Nogueira, C., Lauretti, G., \& Costa, R. (2005). Avaliação duplamente encoberta da hipnose em fibromialgia. São Paulo Medical Journal, 14(supl. 1), 123.

Patterson, D. (2004). Treating pain with hypnosis. Current Directions in Psychological Science, 13(6), 252-255.

Rossi, E., \& Cheek, D. (1988). Mind-body therapy. New York: Norton.

Roustang, F. (1991). L'influence. Paris: Minuit.

Roustang, F. (2000). La fin de la plainte. Paris: Odile Jacob.

Roustang, F. (2006). Savoir attendre pour que la vie change. Paris: Odile Jacob.

Sartre, J-P. (2005). L'Imaginaire ( $3^{\text {a }}$ ed.). Paris: Flammarion.
Stengers, I. (2001). Qu'est-ce que l'hypnose nous oblige à penser? Ethnopsy: les mondes contemporains de la guérison, 3, 13-68.

Stengers, I. (2002). L'hypnose: entre magie et science. Paris: Seuil/Synthelabo.

Turk, D., Swanson, K., \& Tunks, E. (2008). Psychological approaches in the treatment of chronic pain patients - when pills, scalpels and needles are not enough. The Canadian Journal of Psychiatry, 53(4), 213-223.

White, M. (2007). Maps of narrative practice. New York: Norton \& Company.

Zeig, J. (2006). Confluence: The selected papers of Jeffrey $K$. Zeig. Phoenix: Zeig, Tucker \& Theisen, Inc.

Zeig, J., \& Geary, B. (2000). The letters of Milton Erickson. Phoenix: Zeig, Tucker \& Theisen, Inc. 